\title{
Innovative development in business operation of the Thai auto parts industry
}

\author{
Pisit Potjanajaruwit ${ }^{1, *}$ \\ ${ }^{1}$ Suan Sunandha Rajabhat University, Thailand
}

\begin{abstract}
This research study aims to study the direct effect, indirect effect, and total effect of cause and effect factors of innovation development in the business operation of the Thai auto parts industry. This research is quantitative research using questionnaires from a sample of 360 sites and qualitative research by in-depth interviews with ten auto parts industry executives in Thailand. Statistics in the affirmative element analysis and the causal relationship structure analysis. The results showed that the causal factors of technology had a positive direct effect on the development of business innovation and the development of business innovation had a positive direct effect on the business advantage of the competition of establishments in the auto parts industry was statistically significant at the level of 0.05 .
\end{abstract}

\section{Introduction}

Eastern Economic Corridor (EEC) is an important part of building private investors' confidence promoting through infrastructure and tax incentives.

In the EEC area there is a long-term development is accelerated, new industrial development S-Curve, with its heavy use of innovation, will face the challenge of Thailand's more competitive innovation readiness. This requires the integration of cooperation from all sectors to sustain industrial development in the future [1]. This makes Thailand's auto parts industry the center for auto parts production in ASEAN and one of the world's global sourcing.

In 2017 Thailand ranked as the No.1 exporter of all types of parts in ASEAN and the 14th global exporter of parts. This stimulates the development of parts manufacturers throughout the supply chain.

However, the collaboration of the automotive industry depends on cooperation to develop towards innovation and win mutual benefits, which stimulates the development of parts manufacturers throughout the supply chain [2]. In line with a study by $[3,4]$ found that the ability of organizations to research and develop the capabilities of technology to create innovation has influenced the competitive advantage of Auto parts industry.

Moreover, [5] studied the effectiveness of technological innovation through organizational learning, where sufficient work was correlated with the performance of technological innovation, in line with [6,7] presented the organization's performance.

\footnotetext{
*Corresponding authors: pisit.po@ssru.ac.th
} 
Betterment, when it comes to a flexible marketing orientation, learning organization, and innovation impact business performance to create a competitive advantage in the manufacturing industry automotive part.

Based on the problems mentioned above and the reasons, the researcher wants to study the structural equation model of innovation development in the business operation of the Thai auto parts industry so that the organization has developed innovative technologies that result in a competitive advantage.

\section{Methodology}

This research was conducted by using a mixed research methodology, namely

1. Quantitative research by studying secondary sources such as books, journals, related research, and using questionnaires to find answers about the causes and effects of innovation in the business operation of the industry in the Thai automotive part. Including concepts and collecting data for analysis by using statistical analysis and structural equation model (Structural Equation Model: SEM.)

2. Qualitative research which uses In-Depth interviews Interview) Ten executives of the Thai logistics service industry to confirm the quantitative research results of the consistency between innovation development variables in the Thai auto parts industry's business operation with guidelines in the research are as follows.

\subsection{Research tools}

1) The researcher has collected data from related research theoretical concepts in the construction of questionnaires to know the relationship of internal and external latent variables and observe variables for development into a query structure.

2) Prepare a questionnaire according to the structure studied by the researcher and bring it to 5 relevant experts from academics and executives involved in the auto parts industry to examine the IOC's confidence value to verify corresponds to the question that the researcher has put up with the research objectives determined by the researcher and corresponds to the problem of the research. The values obtained must be between $0.5-1$ if the value is below 0.5 should the new questions must be revised to reflect the objectives to be measured.

3) The questionnaires were improved according to expert recommendations and applied to 30 samples before the actual use to verify each question is exact and the same line and direction.

4) The results obtained from the collected data of 30 samples were examined for Cronbach Alpha's Reliability (Cronbach 'alpha) with a confidence value of 0.70 or more is considered to have high confidence [6] able to be used to collect the actual data until the deadline is reached.

\subsection{Population and sampling}

This study's population is the Thai auto parts industry, which is the number of auto parts manufacturers of $1,2,3$ population, or the analysis unit in this research is a manager or supervisor or an engineer in the Thai auto parts industry. Divided into auto parts manufacturers No. 1 (Tier -1 ) is a manufacturer that produces high-quality parts according to the specified standards of automotive manufacturers for use in automotive assembly plants (the OEM market) and sells as replacement parts (REM market). 
Seven hundred twenty cases and most of the 2,3 auto parts manufacturers (Tier-2 and Tier -3) are Thai SMEs with lower investment in research and development in manufacturing technology than Tier-1. Supply of raw materials and components for Tier-1 manufacturers and replacement or automotive parts (REM market). Currently, there are more than 1,100 operators (Thailand Automotive Institute). Cited in [1].

The researcher defined sample size as a ratio to the number [7], explaining that considering the sample size versus the number of required independent parameters, the study variable should be a ratio of 20 samples to 1 of the [7,8] variables using a 20 ratio criterion. Therefore, the researcher has studied empirical or (Observed Variable) the total number of 15 variables. So, the total number of samples required for all requirements was 300 samples $(15 \times 20=300)$, plus 60 samples of error risk, and all samples were obtained $(300+60=360)$.

\subsection{Data analysis}

The researcher chose to use a software package to analyze the relationship of variables and apply the Structural Equation Model (SEM) or the causal relationship structure analysis between variables.

Measurement model using confirmatory factor analysis (CFA) in Structural Equations Model (SEM) to answer research questions about the model causality. Moreover, were defined the measurement level properties by multiple regression analysis, factor analysis, and Path Analysis.

\section{Results}

From the analysis of data, structure equation model, innovation in the business operation of the Thai auto parts industry, both cause and effect factors, it was found that latent variables that were related to each other, such as technology latent variables, had an effect on Competitive Advantage Technology has a standard regression coefficient of 0.42 . Technology latent variables impact on innovation has a standard regression coefficient of 0.67 , and innovation affects the competitive advantage of the company has a standard regression coefficient of 0.38 .

Results of hypothesis testing by considering t-test (CR) values, P-Value and the correlation of variables in each pair, the relationship between independent and dependent variables, and the evaluation of the influence between variables obtained from the standard regression coefficient of the variables.

The predictive parameters are 1) Technology 2) Innovation and internal latent variables are the competitive advantages in the auto parts industry in Thailand using the method of estimation of the maximum probability parameter (Maximum Likelihood : ML).

The results of the data analysis were presented in Figure 1 The hypothesis testing results and the results of investigating the influence of the predictive variable on the variables were found that the standard regression coefficients (coef.) Each correlation path was based on the assumption. The research showed that the t-test (CR) was statistically significant, i.e., $t-$ test (CR) was greater than 1.96 for all values, resulting in the analysis results supporting all hypotheses, hypothesis test results the influence of the researcher variables as shown in Table 1. 


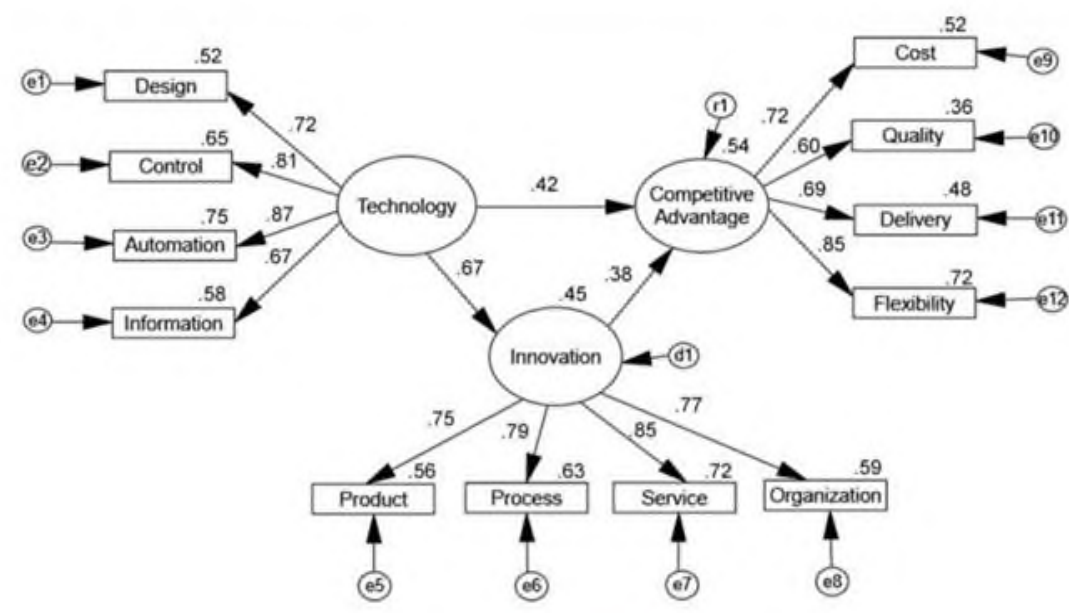

Chi-square $\left(\chi^{2}\right)=53.173, \mathrm{df}=42, \mathrm{p}=.116, \mathrm{CMIN} / \mathrm{DF}\left(\chi^{2} / \mathrm{df}\right)=1.266, \mathrm{GF} \mid=.960, \mathrm{CF}=.992$, AGFI $=.925, \mathrm{NF} \mid=.962$ and $\mathrm{RMSEA}=.037$

Fig. 1. Structural equation model analysis results.

Table 1. Hypothesis test results.

\begin{tabular}{|l|c|c|c|c|}
\hline \multicolumn{1}{|c|}{ Hypothesis } & $\begin{array}{c}\text { Standard } \\
\text { regression } \\
\text { coefficient } \\
\text { (coef.) }\end{array}$ & C.R & p & Results \\
\hline $\begin{array}{l}\text { Hypothesis 1: Technology has a positive } \\
\text { direct effect on Innovation. }\end{array}$ & 0.671 & 8.267 & $* * *$ & Support \\
\hline $\begin{array}{l}\text { Hypothesis 2: Technology has a positive } \\
\text { direct effect on competitive advantage. }\end{array}$ & 0.422 & 4.231 & $* * *$ & Support \\
\hline $\begin{array}{l}\text { Hypothesis 3: Technology has a positive } \\
\text { direct effect on competitive advantage. }\end{array}$ & 0.385 & 3.775 & $* * *$ & Support \\
\hline
\end{tabular}

Remark *** Statistical significance level 0.01 .

Table 2. Direct, Indirect and Total Effect.

\begin{tabular}{|c|c|c|c|c|}
\hline \multirow{2}{*}{ Dependent variable } & \multirow{2}{*}{$\mathbf{R}^{2}$} & \multirow{2}{*}{ Effect } & \multicolumn{2}{|c|}{ Independent variables } \\
\hline & & & Technology & Innovation \\
\hline \multirow{3}{*}{ Innovation } & \multirow{3}{*}{0.452} & $\overline{\mathrm{DE}}$ & .671 & .000 \\
\hline & & IE & .000 & .000 \\
\hline & & TE & .671 & .000 \\
\hline \multirow{3}{*}{ Competitive Advantage } & \multirow{3}{*}{0.544} & $\mathrm{DE}$ & .422 & .385 \\
\hline & & IE & .258 & .000 \\
\hline & & TE & .680 & .385 \\
\hline
\end{tabular}

Direct Effect

Hypothesis 1: Technology had a positive direct effect on innovation; the hypothesis test found that the standard regression coefficient (coef.) $=0.671$, accepted the hypothesis at the statistical significance level of 0.05 .

Hypothesis 2: Technology had a positive direct effect on competitive advantage; the hypothesis test results showed that the standard regression coefficient (coef.) $=.422$ had the accepted reality of the statistical significance level of 0.05 . 
Hypothesis 3: Innovation had a positive direct effect on competitive advantage. The hypothesis test showed that the standard regression coefficient (coef.) $=.385$ was actual, accepted according to the statistical significance level hypothesis of 0.05 .

Indirect Effect

The structural equation model testing and hypothesis testing showed that the predictive variable indirectly affects the dependent variable through the interstitial variable was statistically significant at 0.05 by using coef. Multiply them [6] as follows: Technology indirectly affect competitive advantage through Innovation $=(0.671)(0.385)=0.258$.

Total Effect

Technology has a total effect on competitive advantage as follows: Direct influence $=0.422$ Indirect influence $=0.258$ Total influence $=0.680$.

\section{Discussion}

According to the analysis, most respondents held 126 leadership positions, representing 42.00 percent of whom were 177 males. Revenue accounted for $59.00 \%$, most of whom are between 40-49 years of age, 156 cases, $52.00 \%$. Most of them have work experience. Between 10-20 years, there were 149 cases, $49.67 \%$. The highest level of education was 191 cases of bachelor's degree, $63.67 \%$. Responding to the questionnaire, focusing on the development of innovation in business operations as a factor that affects the competitive advantage of the Thai auto parts industry at a high level, it has a mean of 4.200 , a standard deviation of .477 .

In this research study, the researcher determined the research objectives to study the influence of cause and effect factors of innovation development in the Thai auto parts industry's business operation. A direct positive influence on innovation development has a standard regression coefficient (coef.) $=0.671$.

This is consistent with the research of [8], which studies research and development capabilities, technology capabilities, and innovation capabilities for a competitive advantage in the auto parts industry and [9], has found that technological innovations have influenced the growth of auto parts enterprises, in which entrepreneurs who are aware of market opportunities, technological promotion, and technological innovation. It can lead the organization to sales, reliability, and sustainable growth.

Besides, [9] propose that senior management support influences technology skillbuilding, organizational learning technology capabilities, and technological and organizational competence. Therefore, impact on the organization's performance e studied technology that influences technological skills, technological capabilities and organizational learning, thus acknowledging the impact of technology capability and learning - knowing about the innovation of the organization, affecting the performance of the organization.

And $[10,11]$ studied innovation competence technology communication; it was found that a company's talent analysis was related to innovation ability and its impact on the relationship between innovation ability. However, researcher is also found that offer support for the development of technology management and technological capabilities, influence innovation, promote change, and link management.

Strategy Organizational management and control, including the development of resources in various fields to achieve effective operations.

Moreover, the development of innovation directly affects the business's competitive advantage with the standard regression coefficient (coef.) $=.385$, statistically significant at .05 . In line with research by $[12,13]$, the relationship between knowledge management processes and organizational efficiency through organizational innovation has implications 
for the impact of knowledge management on organizational innovation and organizational performance and effect on organizational innovation $[14,15,16]$.

Through innovation in the organization to the relationship between knowledge management and organizational efficiency [17]. The researcher also examines the relationship of delivery service innovation to a sustainable competitive advantage and the role of customer and business partner alignment in its implementation. It found Jobs driven by delivery service innovation have demonstrated that the approach to strengthening technology, knowledge, marketing innovation is associated with service delivery innovation, leading to planning to company strategy and resource allocation for sustainable growth.

\section{References}

1. A. Petcharit et al., Intern. J. of Online and Biomedical Engineering 16(02), 131-145 (2020)

2. W. Liu, Y. Wang, Intern. J. of Production Economics 161, 181-191 (2015)

3. H. Van et al., Journal of International Studies 10(4), 109-118 (2017)

4. W. Chamsuk et al., The effects of $R \& D$ and innovation capabilities on the Thai automotive industry part's competitive advantage: a SEM approach (2017)

5. B. Hu, European Management Journal 32(4), 587-595 (2014)

6. D. Ushakov et al., Intern. J. of Ecological Economics and Statistics 38(4), 164-172 (2017)

7. J. Henseler et al., New challenges to international marketing (Emerald Group Publishing Limited, 2009)

8. M Ermilova et al., Opcion 34(SI 17), 1074-1087 (2018)

9. J. Hair et al., Multivariate Data Analysis (Upper Saddle River, NJ: Prentice-Hall, 2010)

10. R.E. Schumacker, R.G. Lomax, A beginner's guide to structural equation modeling (Psychology press, 2004)

11. Z. Dong et al., J. of cleaner production 231, 196-206 (2019)

12. P. Gohoungodji et al., J. of Cleaner Production 123, 524 (2020)

13. A. Onofre et al., J. of Cleaner Production 272, 122987 (2020)

14. C. Yu et al., The EUrASEANs: J. on Global Socio-Economic Dynamics 1(2), 20-30 (2017)

15. X. Li et al., China Economic Review 59, 101382 (2020)

16. K. Krishnaswamy et al., Technology in Society 38, 18-31 (2014)

17. C. Lauaro, V. Vinzi, Contributions to Pls Path Modeling and System for the European Customer Satisfaction (2004) 